\title{
Women In Engineering: Insight Into Why Some Engineering Departments Have More Success In Recruiting And Graduating Women
}

Jean Bossart, University of Florida, USA

Neelam Bharti, University of Florida, USA

\begin{abstract}
Universities across the United States (U.S.) are perplexed as to why fewer women than men study engineering and why even fewer complete the curriculum and earn an undergraduate degree in engineering. The percentage of undergraduate engineering degrees awarded annually to women in the U.S. since 2000 has remained relatively constant at around $20 \%$. However, some engineering disciplines have had much greater success in graduating women, with some programs awarding 50\% or more of their bachelor's degrees to women. The purpose of this research was to gain a better understanding of why women preferred certain engineering disciplines over others. Up to 17 years of undergraduate engineering department data from the University of Florida (UF) and national averages from the National Science Foundation (NSF) were reviewed to evaluate graduation rates for women in engineering. The total number of graduates at the undergraduate level were compared to the number of undergraduates who identified themselves as women. Linear regression of the data was used to identify trends. In the last 17 years, there has been little change in the overall percentage of women engineering undergraduates, but there is a great disparity between the engineering disciplines. Women earn larger proportions of undergraduate degrees in engineering disciplines where they perceive a societal benefit. How can engineering departments improve their enrollment and retention of women? One way is by providing early-on specific real life examples of how engineers solve society's most challenging problems.
\end{abstract}

Keywords: Women In Engineering; Recruiting And Graduating Women; Engineering Departments; Data Comparison

\section{INTRODUCTION}

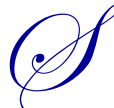

ince the year 2000, the number of undergraduate engineering degrees awarded annually in the United States (U.S.) has remained relatively constant, each year accounting for approximately 4.6 percent (\%) of all bachelor's degrees. However, this consistency also includes a persistent gender gap. For the past 17 years, women received, on average, only $19.6 \%$ of all undergraduate engineering degrees, with a low of $18.1 \%$ in 2009 and a high of $20.9 \%$ in 2002 . This is in contrast to other non-engineering science disciplines, where women accounted for some $80 \%$ of undergraduate degrees in health professions and $58 \%$ in biology (NSF, 2017). However, engineering is not alone in seeing a decline in women graduates; fewer women are graduating with degrees in computer sciences, mathematics, physics, and economics (NSF, 2016). Although in the last 17 years there has been little change in the overall percentage of women engineering graduates, some engineering disciplines have had much greater success in graduating women, with several programs awarding nearly $50 \%$ or more of their bachelor's degrees to women. Success in this context refers to graduation rates for women that reflect the overall student demographic in U.S. universities.

In this article, we assessed undergraduate engineering degrees awarded to women, comparing the national averages for the U.S. against those at the University of Florida (UF), a large public university. We obtained data for multiple engineering disciplines and qualitatively evaluated trends over the past 17 years. We also analyzed data from these engineering disciplines to provide perspective on why women select certain engineering disciplines over others and 
include a discussion of factors relevant to women's enrollment and retention in various engineering programs. Finally, we discuss what engineering departments can do to attract and retain more women undergraduates.

\section{Purpose}

The purpose of this research was to identify trends in enrollment and graduation rates for women undergraduates in various engineering disciplines, comparing the U.S. national data against that for UF. The primary objective was to identify those engineering disciplines that award more undergraduate degrees to women, compared to other engineering disciplines, and to try to ascertain why these programs had such success. Another objective was to develop insight into what priorities women consider when selecting an engineering discipline in which to major. We intend the research to provide guidance to universities in their continuing efforts to attract and retain women in their engineering schools and close the gender gap in engineering education at their home institutions.

To investigate the gender gap in engineering education in the U.S., as well as UF, this research sought to answer the following questions:

1. Which engineering departments nationally have had the most and least success in attracting and graduating women?

2. How do the UF statistics compare to the national averages?

3. What can engineering departments do to attract more women to their undergraduate programs?

\section{Literature Review}

Much research has been conducted on diversity in engineering and in particular, the number of women in engineering. Although, in some undergraduate engineering programs at U.S. universities, women comprise nearly half of the students admitted, but women consistently comprise only about $20 \%$ of the graduates from these programs. The NSF reports that women earn a larger proportion of engineering degrees in chemical, materials, industrial, and civil engineering than in aerospace, electrical, and mechanical engineering and only $14.5 \%$ of employed engineers are women (NSF, 2017).

Mills and Ayre (2003) discuss the lack of growth in the number of women graduates in engineering, as well as the overall lack of diversity in engineering. Further, these authors identified that this plateau for women's involvement has existed for at least 13 years for mechanical, civil, and electrical engineering programs in Australia and the U.S.; a plateau that became evident after nearly 20 years of increasing women's enrollment.

Shealy et al. (2016) studied the expectations of first year college students, both men and women, who intended to major in civil engineering and found that these students expected their engineering careers to involve them in important issues such as water supply and climate change. They also found that women were more likely to show an interest in also working to solve far-reaching societal issues, such as poverty and providing economic opportunities for women and minorities. Ellis, Fosdick, and Rasmussen (2016) found that Calculus I was a reason for women to lose confidence in their ability to continue progressing towards a STEM degree. Women students were 1.5 times more likely to drop out of a STEM program after taking Calculus I.

Orr, Ngambeki, Long, and Ohland (2011) surmised that although women engineering students often earn higher grades than men, the women felt that they have to earn higher grades in order to prove themselves. Meyer and Marx (2014) conducted a qualitative assessment of why undergraduates leave engineering. These authors found that difficulty fitting in was one of the common themes. The extent to which a person defines themselves through a role or performance, such as engineer, is known as domain identification, or in this case engineering identification (Osborne and Jones, 2011). Jones, Ruff, and Paretti (2013) found that engineering identification was the most important factor for retention of women in engineering programs. Ro and Knight (2016) discussed how the literature has indicated that women tend to learn better than man when engaged in socially relevant material. Further, a women's engineering identification may be increased by helping students understand how engineering is useful and increasing their sense of belonging in engineering. Introducing real world applications of engineering early in a student's college career has been shown to improve retention rates of women in STEM disciplines (Hill, Corbett, and St. Rose, 2010). 
Sonnert, Fox, and Adkins (2007) studied the percentages of women undergraduates in science and engineering and correlated the numbers to the percentages of women faculty. They suggested that the observance and interactions with female role models plays a significant part in influencing the number of women undergraduates in science and engineering. Their research indicates that the individual engineering departments play a stronger role in the number of women undergraduate degrees awarded as opposed to the wider engineering college. Su, Johnson, and Bozeman (2015) also focused on academic departments and found that the department chairs can influence gender diversity among their faculty but that women department chairs did not necessarily translate to an increase in the number of women faculty. Blaney et al. (2016) reported that in 2013 , approximately $46 \%$ of all environmental engineering degrees were earned by women, but only $15 \%$ of full professors in these departments were women. The percentage of women earning engineering degrees does not increase even when the dean of engineering is a woman (Meiksins, Layne, Camargo, and Snead, 2013).

\section{METHODS}

Seventeen years of data from the academic years of 2000 through 2016 were analyzed for the number of women undergraduates of the various engineering departments at UF. These statistics are maintained by the College of Engineering for each of the departments within the college. Additional data was obtained from the UF Office of Institutional Planning and Research. Data were also obtained from 2000 through 2014 from NSF's National Center for Science and Engineering Statistics, Completions Survey. No national percentage data were available as of the date of this publication from NSF for 2015 or 2016.

U.S. data presented are for the aggregate United States, which comprises the 50 states, the District of Columbia, and the U.S. territories and outlying areas (American Samoa, the former Canal Zone, Guam, the Northern Mariana Islands, Puerto Rico, the U.S. Virgin Islands, and the Trust Territory of the Pacific Islands).

Both the U.S. and UF data are compiled for a 12-month academic year, July of one year through June of the following year. For example, degrees in a given July-through-June period are referred to by the year in which the period ended. For example, 2012 means the 12-month period beginning July 1, 2011 and ending June 30, 2012.

The total number of engineering graduates at the undergraduate level were compared to the number of undergraduates who identified themselves as women. UF statistics were compared to national statistics from the NSF's National Center for Science and Engineering Statistics

\section{RESULTS AND DISCUSSION}

Since 2000, the number of bachelor's degrees in the U.S. awarded in engineering has increased; however, the percentage of those degrees awarded to women has stayed the same. The percentage of undergraduate engineering degrees awarded to women ranged from $18 \%$ to $21 \%$, with average of $19.5 \%$ and no discernable trends. Figure 1 shows the fluctuations in the number of degrees awarded to women. 
Figure 1. Total number of engineering degrees awarded to women in the U.S. from 2000 to 2014

\section{B.S. Engineering Degrees Awarded}

to Women in the U.S.

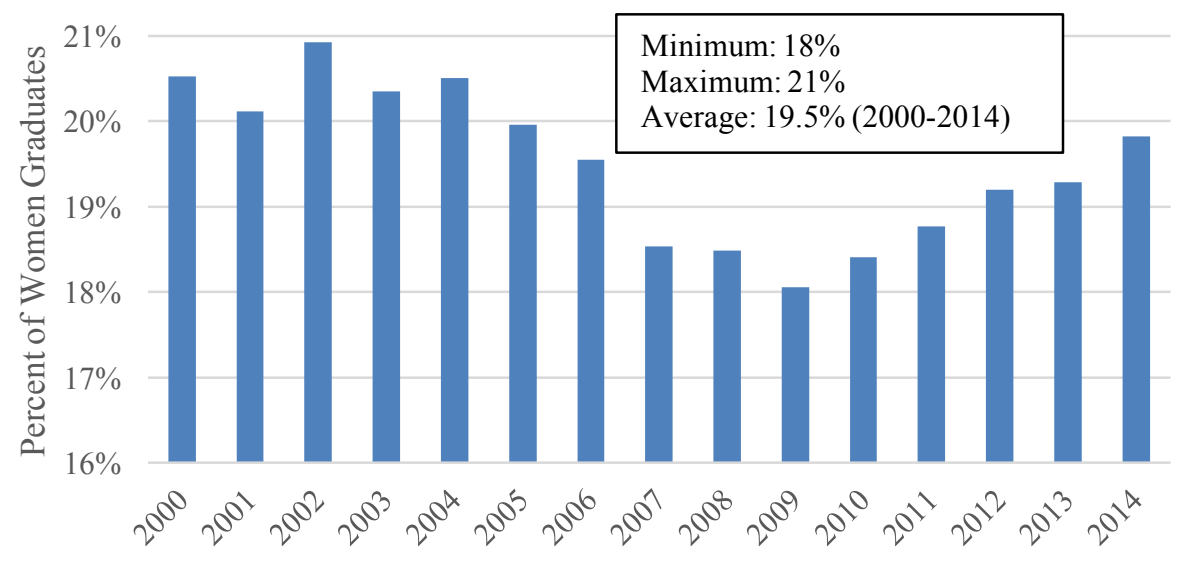

\section{Core Engineering Disciplines}

Data were evaluated for the core engineering disciplines to assess by discipline the number of women graduates. UF bachelor's degrees awarded were compared to national data from the NSF. NSF maintains data for the following seven engineering disciplines: aerospace, chemical, civil, electrical, industrial, materials, and mechanical. Table 1 provides a comparison of the percentages of bachelor's degrees awarded to women in these seven engineering disciplines.

Table 1. Bachelor's degrees awarded to women in the U.S. and at UF, by engineering discipline: 2000-2016

\begin{tabular}{|c|c|c|c|c|c|c|c|c|}
\hline & 2000 & 2001 & 2002 & 2003 & 2004 & 2005 & 2006 & 2007 \\
\hline \multicolumn{9}{|c|}{ Aerospace } \\
\hline U.S. & $19 \%$ & $20 \%$ & $18 \%$ & $19 \%$ & $18 \%$ & $17 \%$ & $18 \%$ & $16 \%$ \\
\hline UF & $8 \%$ & $25 \%$ & $35 \%$ & $33 \%$ & $10 \%$ & $24 \%$ & $20 \%$ & $15 \%$ \\
\hline \multicolumn{9}{|c|}{ Chemical } \\
\hline U.S. & $36 \%$ & $35 \%$ & $37 \%$ & $38 \%$ & $35 \%$ & $36 \%$ & $35 \%$ & $34 \%$ \\
\hline UF & $34 \%$ & $17 \%$ & $27 \%$ & $36 \%$ & $29 \%$ & $39 \%$ & $23 \%$ & $30 \%$ \\
\hline \multicolumn{9}{|c|}{ Civil } \\
\hline U.S. & $23 \%$ & $24 \%$ & $23 \%$ & $23 \%$ & $24 \%$ & $24 \%$ & $23 \%$ & $22 \%$ \\
\hline UF & $16 \%$ & $23 \%$ & $32 \%$ & $15 \%$ & $17 \%$ & $24 \%$ & $24 \%$ & $19 \%$ \\
\hline \multicolumn{9}{|c|}{ Electrical } \\
\hline U.S. & $14 \%$ & $14 \%$ & $15 \%$ & $15 \%$ & $14 \%$ & $13 \%$ & $13 \%$ & $11 \%$ \\
\hline UF & $11 \%$ & $12 \%$ & $14 \%$ & $10 \%$ & $9 \%$ & $10 \%$ & $6 \%$ & $9 \%$ \\
\hline \multicolumn{9}{|c|}{ Industrial } \\
\hline U.S. & $33 \%$ & $32 \%$ & $34 \%$ & $33 \%$ & $33 \%$ & $32 \%$ & $30 \%$ & $30 \%$ \\
\hline UF & $22 \%$ & $34 \%$ & $33 \%$ & $38 \%$ & $34 \%$ & $34 \%$ & $40 \%$ & $29 \%$ \\
\hline \multicolumn{9}{|c|}{ Materials } \\
\hline U.S. & $30 \%$ & $31 \%$ & $33 \%$ & $30 \%$ & $31 \%$ & $31 \%$ & $27 \%$ & $27 \%$ \\
\hline UF & $41 \%$ & $35 \%$ & $35 \%$ & $45 \%$ & $44 \%$ & $22 \%$ & $39 \%$ & $24 \%$ \\
\hline \multicolumn{9}{|c|}{ Mechanical } \\
\hline U.S. & $14 \%$ & $13 \%$ & $13 \%$ & $13 \%$ & $14 \%$ & $13 \%$ & $13 \%$ & $12 \%$ \\
\hline UF & $4 \%$ & $14 \%$ & $15 \%$ & $11 \%$ & $13 \%$ & $18 \%$ & $14 \%$ & $19 \%$ \\
\hline
\end{tabular}

(Table 1 continued on next page) 
$\underline{\text { (Table } 1 \text { continued) }}$

\begin{tabular}{|c|c|c|c|c|c|c|c|c|c|}
\hline & 2008 & 2009 & 2010 & 2011 & 2012 & 2013 & 2014 & 2015 & 2016 \\
\hline \multicolumn{10}{|c|}{ Aerospace } \\
\hline U.S. & $15 \%$ & $14 \%$ & $14 \%$ & $13 \%$ & $13 \%$ & $14 \%$ & $14 \%$ & $\mathrm{~N} / \mathrm{A}$ & N/A \\
\hline UF & $16 \%$ & $9 \%$ & $5 \%$ & $7 \%$ & $14 \%$ & $18 \%$ & $8 \%$ & $21 \%$ & $12 \%$ \\
\hline \multicolumn{10}{|c|}{ Chemical } \\
\hline U.S. & $33 \%$ & $33 \%$ & $32 \%$ & $31 \%$ & $30 \%$ & $30 \%$ & $31 \%$ & $\mathrm{~N} / \mathrm{A}$ & N/A \\
\hline UF & $15 \%$ & $23 \%$ & $28 \%$ & $36 \%$ & $34 \%$ & $25 \%$ & $33 \%$ & $31 \%$ & $36 \%$ \\
\hline \multicolumn{10}{|l|}{ Civil } \\
\hline U.S. & $22 \%$ & $22 \%$ & $21 \%$ & $22 \%$ & $23 \%$ & $23 \%$ & $24 \%$ & N/A & N/A \\
\hline UF & $23 \%$ & $20 \%$ & $25 \%$ & $19 \%$ & $18 \%$ & $25 \%$ & $30 \%$ & $22 \%$ & $21 \%$ \\
\hline \multicolumn{10}{|c|}{ Electrical } \\
\hline U.S. & $11 \%$ & $10 \%$ & $11 \%$ & $11 \%$ & $11 \%$ & $11 \%$ & $12 \%$ & N/A & N/A \\
\hline UF & $12 \%$ & $12 \%$ & $10 \%$ & $9 \%$ & $10 \%$ & $17 \%$ & $20 \%$ & $14 \%$ & $12 \%$ \\
\hline \multicolumn{10}{|c|}{ Industrial } \\
\hline U.S. & $28 \%$ & $27 \%$ & $27 \%$ & $27 \%$ & $27 \%$ & $27 \%$ & $27 \%$ & N/A & N/A \\
\hline UF & $29 \%$ & $37 \%$ & $33 \%$ & $31 \%$ & $37 \%$ & $29 \%$ & $34 \%$ & $33 \%$ & $35 \%$ \\
\hline \multicolumn{10}{|c|}{ Materials } \\
\hline U.S. & $24 \%$ & $25 \%$ & $26 \%$ & $28 \%$ & $28 \%$ & $30 \%$ & $27 \%$ & $\mathrm{~N} / \mathrm{A}$ & N/A \\
\hline UF & $33 \%$ & $29 \%$ & $37 \%$ & $26 \%$ & $28 \%$ & $28 \%$ & $43 \%$ & $36 \%$ & $33 \%$ \\
\hline \multicolumn{10}{|c|}{ Mechanical } \\
\hline U.S. & $12 \%$ & $11 \%$ & $11 \%$ & $11 \%$ & $12 \%$ & $12 \%$ & $13 \%$ & $\mathrm{~N} / \mathrm{A}$ & N/A \\
\hline UF & $12 \%$ & $12 \%$ & $15 \%$ & $12 \%$ & $16 \%$ & $15 \%$ & $15 \%$ & $16 \%$ & $17 \%$ \\
\hline
\end{tabular}

\section{Aerospace Engineering}

A comparison of the percent of women aerospace engineering graduates nationally and at UF for the years 2000 through 2016 is shown in Figure 2. The overall trends were very similar for the UF and national averages with $16.4 \%$ and $16.1 \%$ of women graduates, respectively. Nationally, for all the examined years, women aerospace engineering graduation rates were consistently $20 \%$ or less. UF displayed substantial fluctuation in its women aerospace engineering graduates, reaching a maximum of $35 \%$ in 2002 but dipping to a low of 5\% in 2010. Graduation rates of women in aerospace engineering displayed a general downward trend both nationally and at UF.

Figure 2. Aerospace engineering degrees awarded to women nationally and at UF from 2000 to 2016

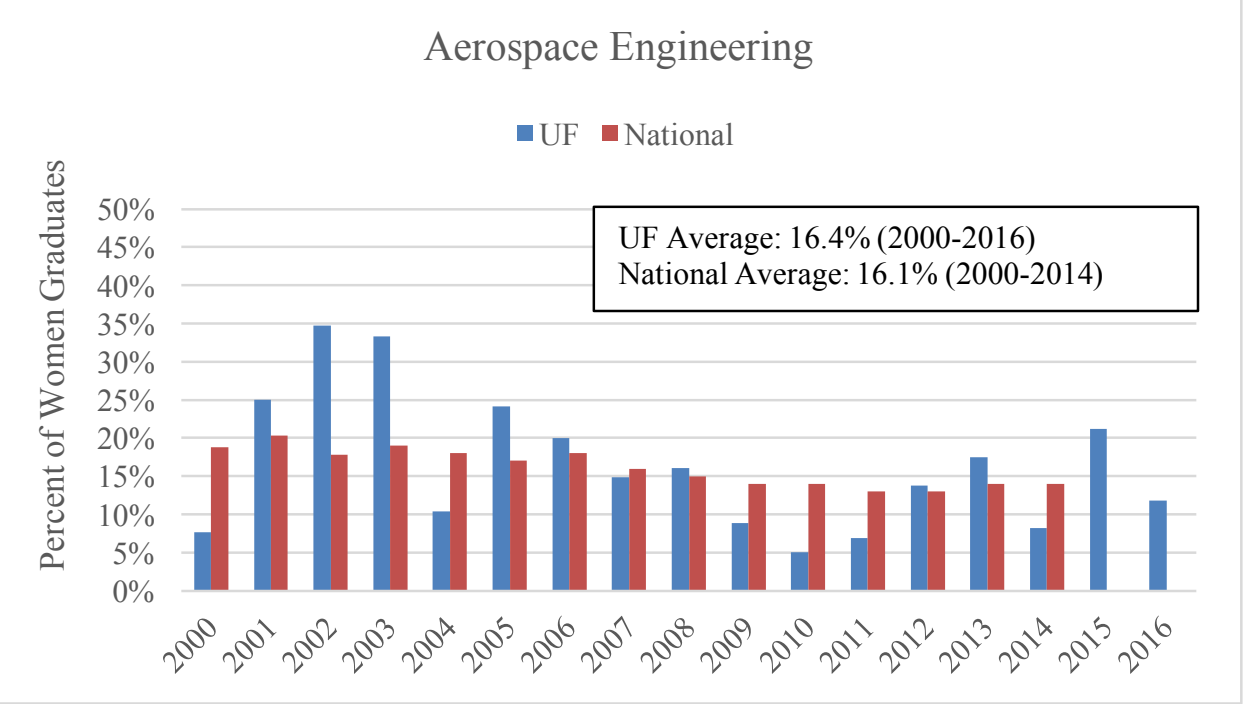




\section{Chemical Engineering}

A comparison of the percentage of women chemical engineering graduates nationally and at UF for the years 2000 through 2016 is provided in Figure 3. During this time period, the average number of UF graduates at 29.2\% was less than the national average of $33.7 \%$ for 11 of the 15 years for which comparative data were available. Nationally, for all the examined years, chemical engineering graduates were consistently $30 \%$ to $38 \%$ women. However, UF displayed substantial fluctuation in its women chemical engineering graduates, reaching a maximum of $39 \%$ in 2005 but dipping to $15 \%$ in 2008. Despite these fluctuations, UF women graduates in chemical engineering displayed a general upward trend when viewed across the entire time period, while nationally the trend was slightly downward.

Figure 3. Chemical engineering degrees awarded to women nationally and at UF from 2000 to 2016

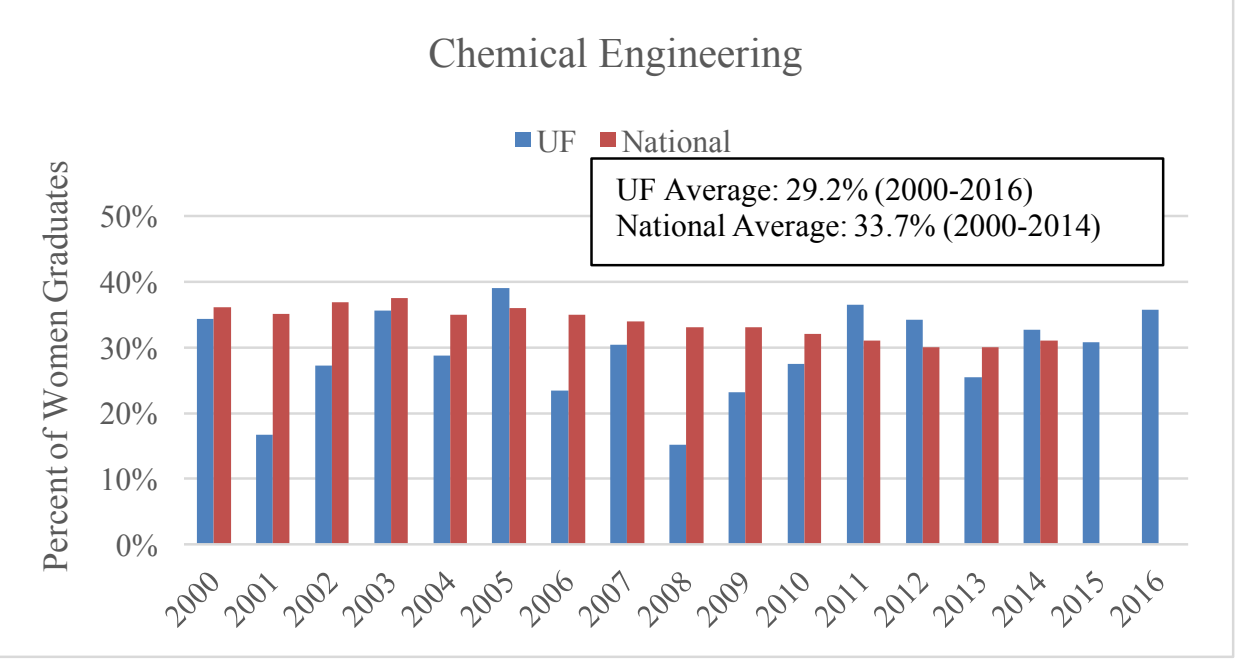

\section{Civil Engineering}

A comparison of the percent of women civil engineering graduates nationally and at UF for the years 2000 through 2016 is shown in Figure 4. The overall trends were similar for the UF and national averages with $21.9 \%$ and $22.9 \%$ of women graduates, respectively. Nationally, for all the examined years, women civil engineering graduation rates were consistently between $21 \%$ and $24 \%$. UF graduation rates of women in civil engineering fluctuated, reaching a maximum of $32 \%$ in 2002 and a low of $15 \%$ in 2003; this variability over a one-year period may not be indicative of a trend but rather a localized fluctuation. Graduation rates of women in civil engineering were virtually flat at both the national level and at UF with the exception of years 2002 and 2014, where the graduation rates at UF reached above $30 \%$. 
Figure 4. Civil engineering degrees awarded to women nationally and at UF from 2000 to 2016

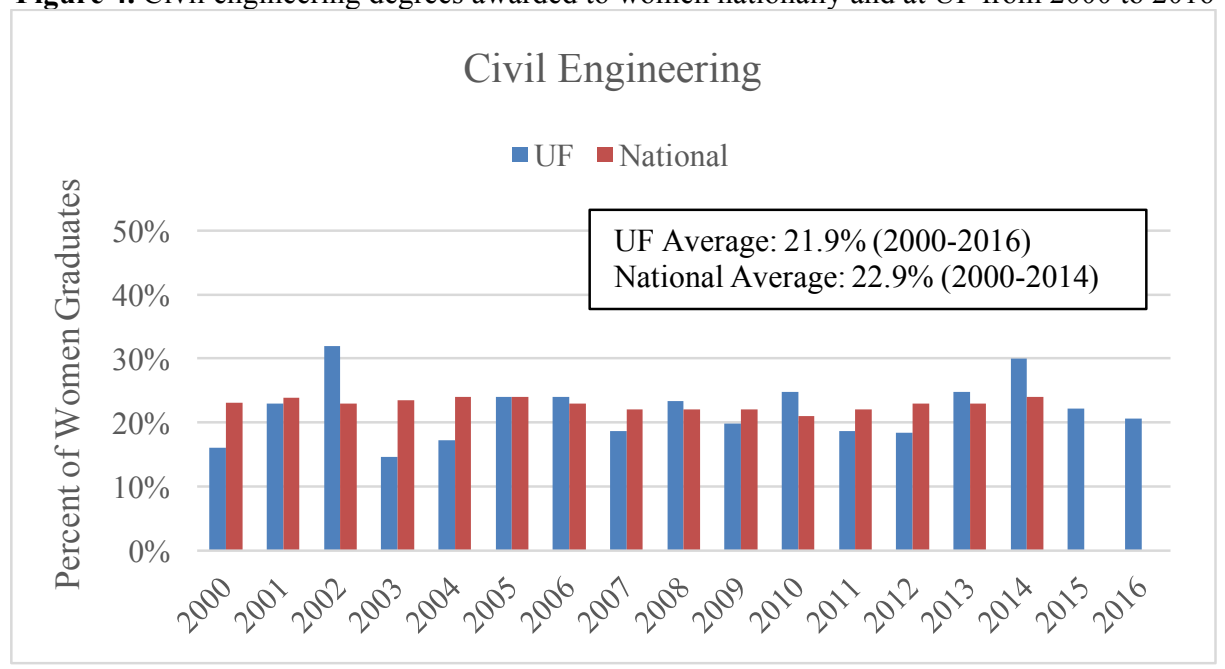

\section{Electrical Engineering}

A comparison of the percent of women electrical engineering graduates nationally and at UF for the years 2000 through 2016 is provided in Figure 5. The overall trends were very similar for the UF and national averages with $11.6 \%$ and $12.4 \%$ of women graduates, respectively. Nationally, for all the examined years, women electrical engineering graduation rates were consistently $15 \%$ or less. UF displayed substantial fluctuation in its women electrical engineering graduates, reaching a maximum of $20 \%$ in 2014 but had been as low as $6 \%$ in 2006. Graduation rates of women in electrical engineering increased at UF beginning in 2013.

Figure 5. Electrical engineering degrees award to women nationally and at UF from 2000 to 2016

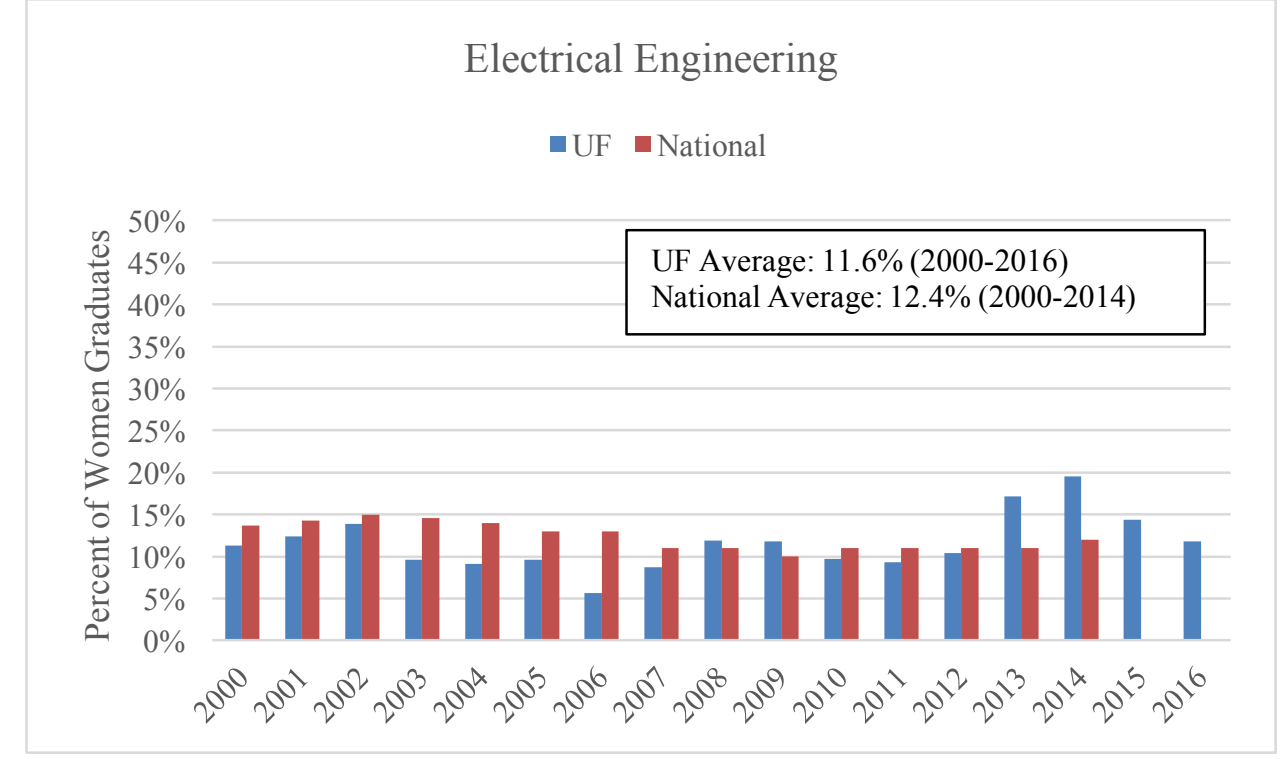

\section{Industrial Engineering}

Industrial engineering degrees awarded to women nationally and at UF from 2000 to 2016 are provided in Figure 2. The overall trends were similar for the UF and national averages with $33.1 \%$ and $29.8 \%$ of women graduates, 
respectively. Nationally, for all the examined years, women industrial engineering graduation rates were consistently between $27 \%$ and $34 \%$ over the 15 -year period. UF graduation rates of women in industrial engineering fluctuated, reaching a maximum of $40 \%$ in 2006 from a low of $22 \%$ in 2000 . Graduation rates of women in industrial engineering fluctuated at UF but showed a general decrease nationally.

Figure 6. Industrial engineering degrees awarded to women nationally and at UF from 2000 to 2016

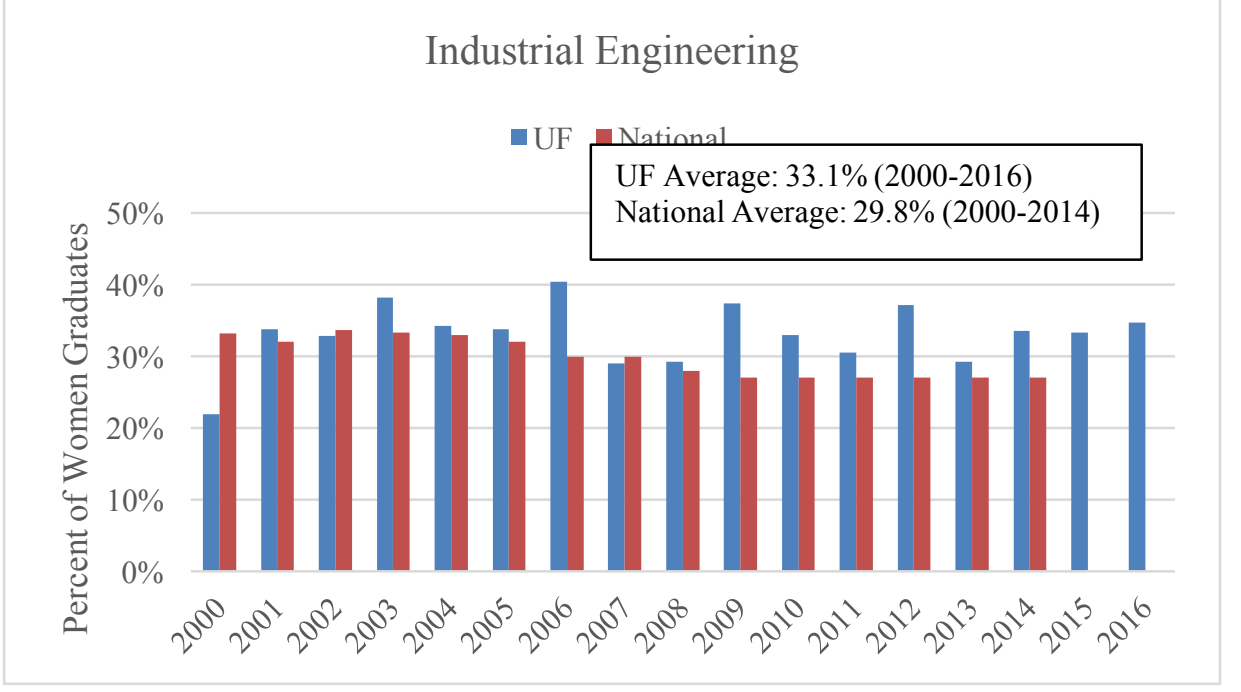

\section{Material Science Engineering}

Material science engineering degrees awarded to women nationally and at UF from 2000 to 2016 are shown in Figure 7. Wide fluctuations in graduation rates for women were observed over the 17 year period. Although the overall trends were similar for the UF and nationally, the average graduation rate was higher at UF at $34 \%$ compared to $28.5 \%$ nationally. The range of graduation rates for women in material science were $22 \%$ to $45 \%$ at UF and $24 \%$ to $33 \%$ nationally.

Figure 7. Material science engineering degrees awarded to women nationally and at UF from 2000 to 2016

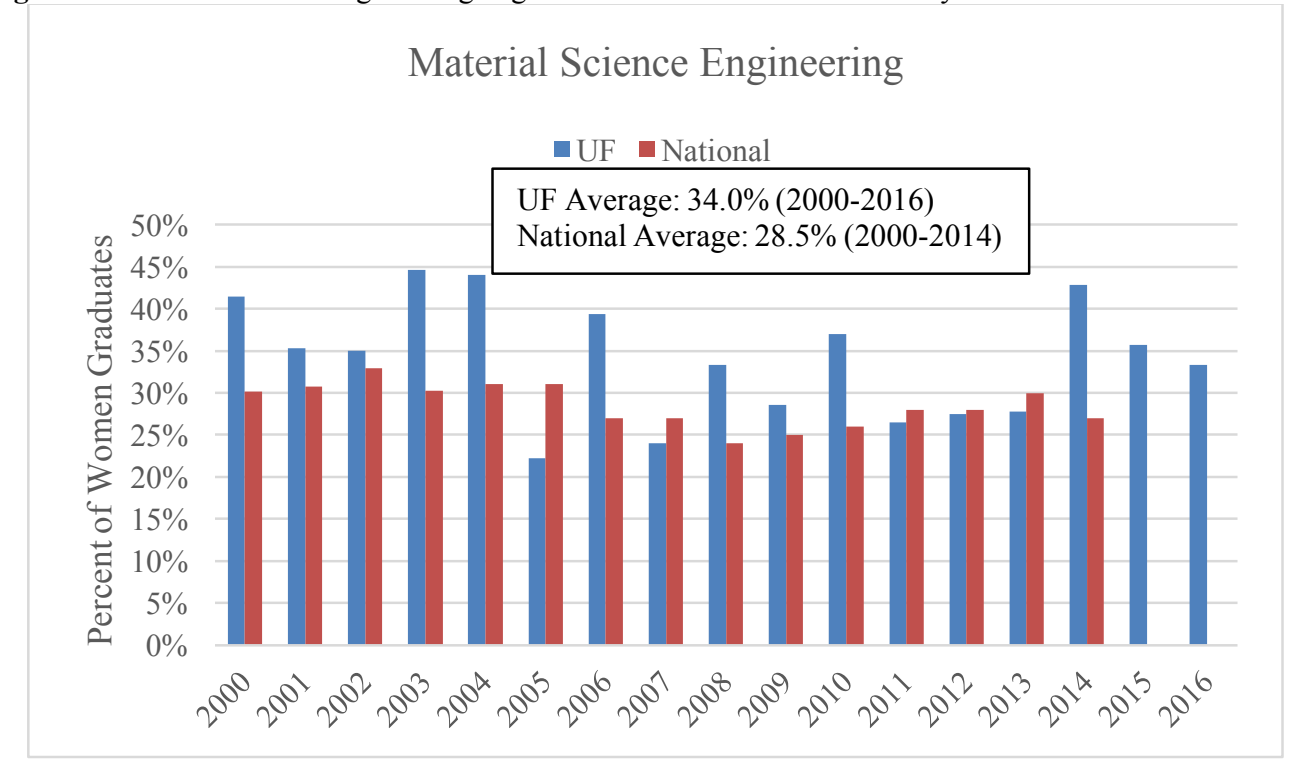




\section{Mechanical Engineering}

Mechanical engineering degrees awarded to women nationally and at UF from 2000 to 2016 are provided in Figure 8 . The UF had a slightly higher graduation rate at $13.9 \%$ for women compared to the U.S. average of $12.5 \%$. Nationally, for all the examined years, women mechanical engineering graduation rates were consistently between $11 \%$ and $14 \%$. UF graduation rates of women in mechanical engineering increased from a low of $4 \%$ in 2000 reaching a maximum of $19 \%$ in 2007. Graduation rates of women in mechanical engineering displayed a slight increase at UF and were virtually flat nationally.

Figure 8. Mechanical engineering degrees awarded to women nationally and at UF from 2000 to 2016

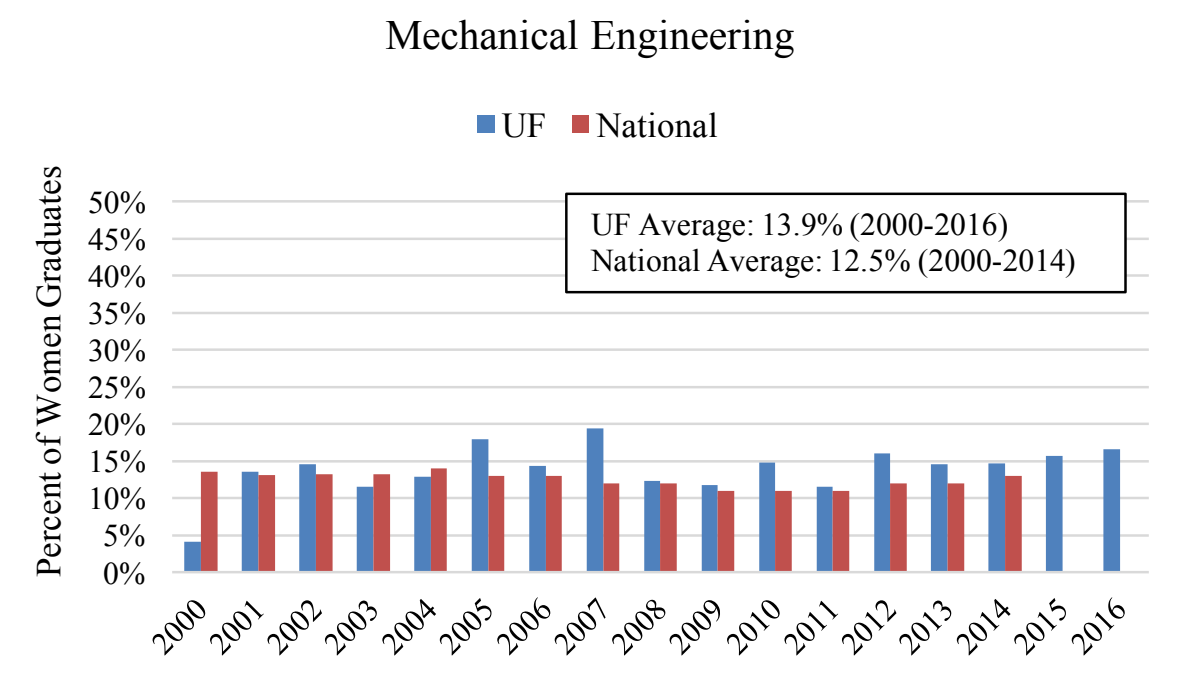

\section{Specialty Engineering Disciplines}

UF, like many other universities offer additional engineering disciplines that reflect regional priorities. Many of these disciplines have had much success in graduating women engineers. Figure 9 shows the percentage of bachelor's degrees awarded to women during the past five years at UF and reflects the latest trends. The top three choices for women were environmental, agricultural \& biological, and biomedical engineering, none of which are any of the seven core programs discussed above. 
Figure 9. Popularity of engineering disciplines among women at UF from 2012 to 2016

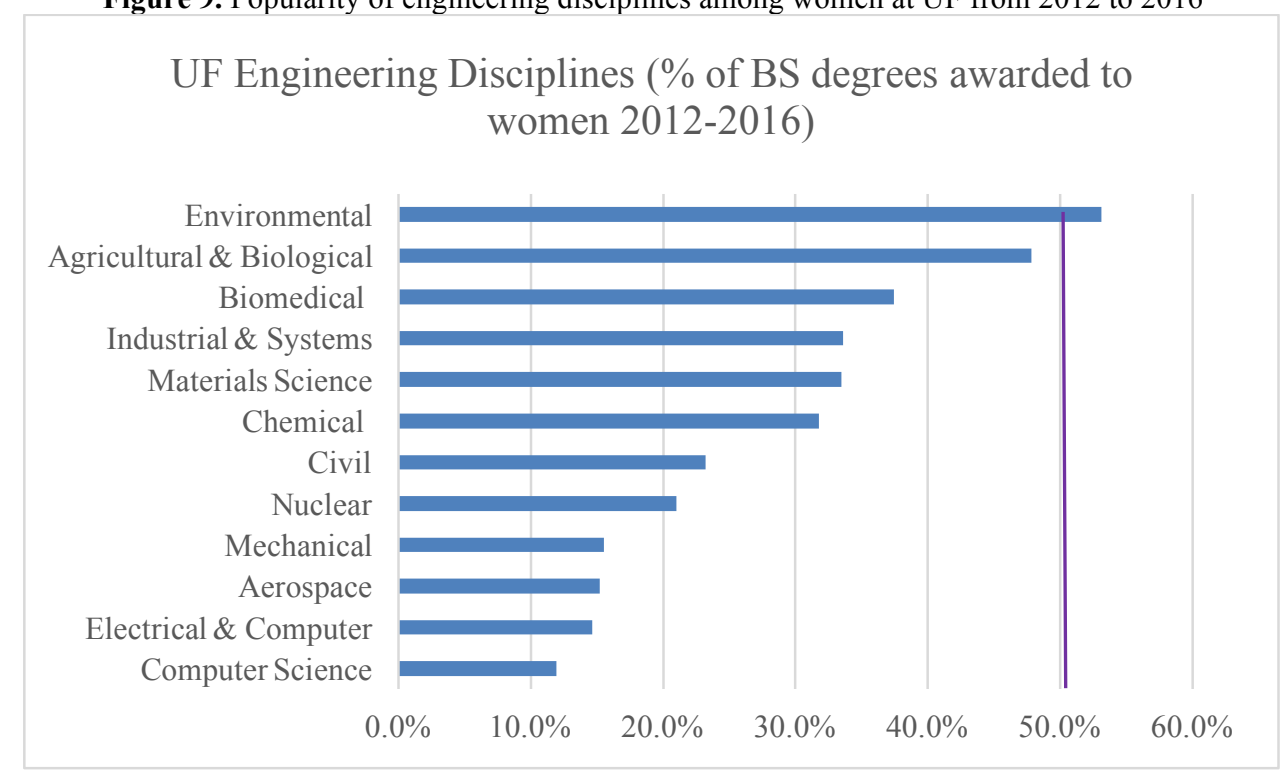

Environmental engineering has had more success in attracting and retaining women than any other engineering department, awarding 50\% or more of its bachelor's degrees to women in 9 of the 17 years since 2000 and in 4 of the last 5 years. As shown in Figure 10, there has been a steady increase in women earning bachelor's degrees in environmental engineering.

Figure 10. Environmental engineering degrees awarded to women at UF from 2000 to 2016

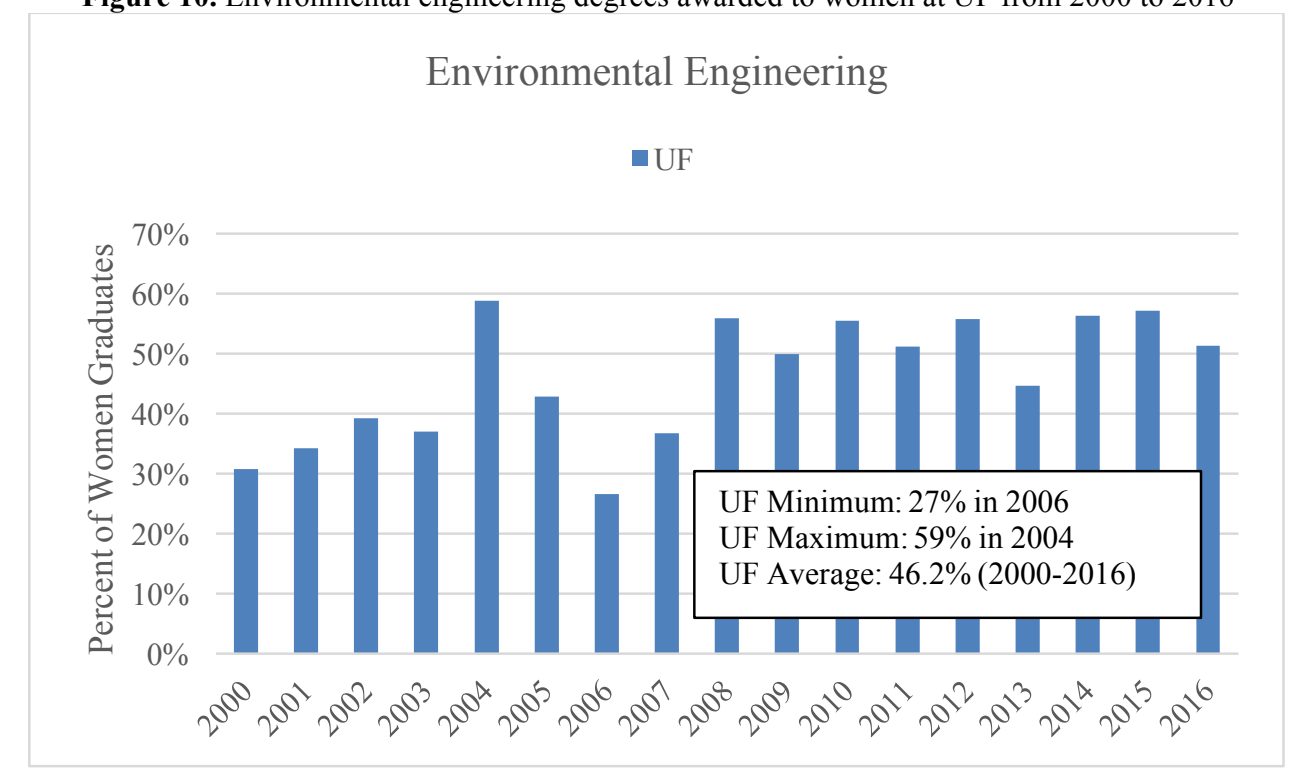

Similarly, during three of the last five years (2012 to 2016), there were more women than men earning bachelor's degrees in agricultural \& biological engineering at UF. As shown in Figure 11, there has been a general increase in women graduates in agricultural \& biological engineering, to where $50 \%$ or more of its bachelor's degrees were awarded to women in the last 3 years. 
Figure 11. Agricultural \& biological engineering degrees awarded to women at UF from 2000 to 2016

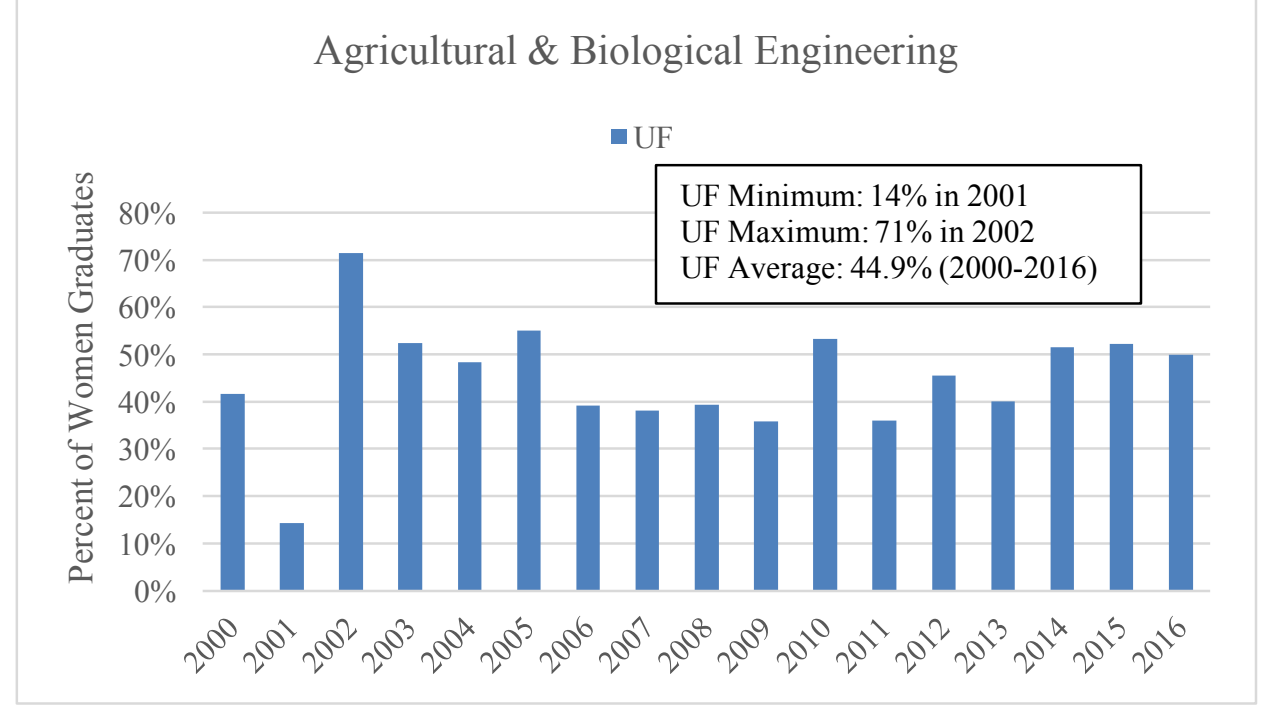

Biomedical engineering, a relatively new discipline at the undergraduate level, has also shown success in graduating women. At the bachelor's level, it has only been around for a short time but looks to have promise as another engineering department in achieving full integration of women. In 2014, 2015, and 2016, women earned 33\%, 48\%, and $31 \%$, respectively of the bachelor's degrees awarded.

\section{DISCUSSION}

Nationally, the annual number of women engineering graduates has remained relatively constant over the past 17 years, plateauing at around $20 \%$. This national trend is mirrored by the statistics for UF. Universities across the U.S., including UF, are perplexed as to why fewer women than men choose to major in engineering, and why even fewer women actually complete an undergraduate engineering degree. These university trends also seem to extend into the workplace, where an NSF study found a substantial number of women who initially start their careers as engineers subsequently leave the engineering work force within 5 years of graduation, such that in 2013 women constituted only $14.5 \%$ of employed engineers (NSF, 2017). Based on 2013 data, women comprised only $8 \%$ of the mechanical engineer workforce and less than 12 percent of the workforce for electrical and aerospace engineers (NSF, 2016).

This research sought to answer the following questions.

\section{Which engineering departments nationally have had the most and least success in attracting and graduating} women?

Of the seven core engineering disciplines -- aerospace, chemical, civil, electrical, industrial, materials, and mechanical, the three that have had the highest graduation rates for women were chemical, industrial, and material science engineering, with national averages of $33.7 \%, 29.8 \%$, and $28.5 \%$, respectively. Conversely, aerospace, electrical, and mechanical engineering had the lowest graduation rates for women, with national averages of $16.1 \%, 12.4 \%$, and $12.5 \%$, respectively. The civil engineering graduation rate for women of $22.9 \%$ was closest to the national average graduation rate for women in all engineering disciplines of $20 \%$.

\section{How do the UF statistics compare to the national averages?}

We found that U.S. and UF graduation rates for the seven core engineering disciplines were similar. UF data represented a much smaller population but the trends were consistent with the national trends. Of the seven core engineering disciplines, the same three, chemical, industrial, and material science, had the highest graduation rates for women, with UF averages of $29.2 \%, 33.1 \%$, and $34.0 \%$, respectively. The same three engineering disciplines with the 
lowest graduation rates for women in both the U.S. and at UF were aerospace, electrical, and mechanical engineering, with UF averages of $16.4 \%, 11.6 \%$, and $13.9 \%$, respectively. The specialty engineering disciplines of environmental, agricultural \& biological, and biomedical engineering had the most success in graduating women at UF. These three programs produced women graduates at the bachelor's level near or exceeding $50 \%$.

\section{What can engineering departments do to graduate more women from their programs?}

Some engineering specialties have had better success in attracting and retaining women, while others struggle in this area. It is important to gain a better understanding of why women prefer certain engineering disciplines to others, and what are the different factors in enrollment and retention. Various studies have found that women favored engineering disciplines they perceive as more socially engaging, working to solve major problems and making a difference in people's lives (Silbey, 2016). This was evident from the percentage of women graduates in environmental engineering, agricultural \& biological engineering, and biomedical engineering, where up to $50 \%$ or more of the undergraduate degrees were awarded to women.

As discussed in the literature review, Sonnert et al. (2007) compared the percentages of women undergraduates in engineering to the percentages of women faculty. They concluded that female role models in the engineering departments played a significant part in influencing the number of women undergraduate degrees awarded. In the top three UF engineering departments where up to $50 \%$ or more of the undergraduate degrees were awarded to women, the percentage of women faculty was also higher than in most of the other engineering departments. In the UF environmental engineering department, $25 \%$ of the faculty are women. Similarly, in the UF biomedical engineering department, $27 \%$ of the faculty are women, including the department chair. Conversely, women comprise only $9 \%$ of the faculty in mechanical and aerospace engineering.

Shealy et al. (2016) concluded that women show a greater interest in working to solve societal issues. One way that engineering departments can improve their enrollment and retention of women is by providing early on, as early as the freshman year, specific real life examples of how an engineering discipline benefits society. Almost all engineering colleges offer an Introduction to Engineering class. As part of this course, providing real life examples of engineering problems could help improve retention and may help women see how some of the traditionally less popular engineering departments contribute to society. In addition to offering a freshman year Introduction to Engineering course, some universities also require their first year students to work on an engineering group project addressing a real-world problem. The University of California Davis offers the hands-on "Design of Coffee" seminar for first year chemical engineering students. The course has grown in popularity from a modest beginning in 2013 when 18 students signed-up to 2015 when more than 1,500 students took the class, some not even engineering students. Fundamental engineering concepts such as heat exchange, leaching, and particle size analysis are taught through the applied lens of coffee production. The course includes a coffee lab, where teams of students start with identical unroasted coffee beans and compete to produce the best-tasting product (Charles, 2016).

At the University of Colorado Boulder, an industry-education partnership for mechanical engineering students provides laboratory space for real-world problem solving (Design Center Colorado, 2016). Through a series of freshmen projects, students get a "taste" of what it will be like to be an engineer, collaborating in interdisciplinary teams to work on societally relevant problems. In addition to learning the fundamentals and problem solving, new engineering students at George Mason University design a prosthetic hand in their freshman introduction to engineering course ENGR 107. This class provides students with the opportunity to gain engineering design experience through a semester design project that emphasizes teamwork, individual contribution, synthesis of key concepts, and creativity (George Mason University, 2015). Students in the Gator Engineering program, taught at Santa Fe College (Gainesville, Florida), take EGN 1935, Introduction to Engineering Design and Programming. In this class they learn how design engineers must consider larger societal issues, such as environmental impact, sustainability, and benefits accruing through technical achievement (UF, 2017a). Also at UF, an undergraduate student club called GRiP designs and builds prosthetic hands for children, sponsoring "hand camps". The club members are primarily undergraduate engineering students and their president and founder is a woman. The UF faculty advisor for GRiP is a librarian who heads the 3D printing laboratory in the science library where GRiP produces the prosthetics (UF 2017b). Many of the students in GRiP are majoring in mechanical engineering. This student organization is an 
excellent example of how to engage women undergraduate engineering students in a group that demonstrates the societal benefits of engineering.

\section{CONCLUSIONS}

In the last 17 years there has been little change in engineering graduation rates for women. There is a great disparity between the engineering disciplines. Women earn larger proportions of undergraduate degrees in chemical, materials, and industrial engineering than in aerospace, electrical, and mechanical engineering. Women earned approximately $50 \%$ of the bachelor's degrees in specialty engineering disciplines such as environmental, agricultural \& biological, and biomedical engineering. Engaging women in their freshmen year in introductory engineering courses, projects, and research that demonstrates how engineering is and has been used to solve some of society's most difficult challenges can help them stay motivated to graduate with an engineering degree. Engineering departments can help motivate women to major in engineering and stay engaged throughout their college careers by providing real-life examples of the societal benefits of engineering.

\section{ACKNOWLEDGEMENT}

The authors would like to thank the UF College of Engineering and Mr. James Ogles, Data Management Analyst for assistance in compiling the UF statistics and Ms. Amy Buhler for her insightful suggestions. Publication of this article was funded in part by the University of Florida Open Access Publishing Fund.

\section{AUTHOR BIOGRAPHIES}

Ms. Bossart is an Associate Engineering Librarian at the Marston Science Library at the University of Florida and is a licensed professional engineer in Florida. She earned a Bachelor's degree in chemical engineering and a Master's degree in environmental engineering and worked as a research and development engineer and engineering consultant before joining the library. E-mail: jean.bossart@ufl.edu (Contact author)

Dr. Bharti is the Chemical Sciences Librarian at the Marston Science Library at the University of Florida. She earned a Ph.D. in medicinal chemistry and worked as a drug development scientist at the University of Florida before joining the library. E-mail: neelambh@ufl.edu

\section{REFERENCES}

Blaney, L., Kandiah, R., Ducoste, J. J., Perlinger, J. A., \& Bartelt-Hunt, S. L. (2016). Trends in population and demographics of US environmental engineering students and faculty from 2005 to 2013. Environmental Engineering Science, 33(8), 578-590. doi:10.1089/ees.2016.0063.

Charles, D. (2016). STEM to steam: how coffee is perking up engineering education. http://www.npr.org/sections/thesalt/2016/09/08/492954687/how-coffee-is-perking-up-engineering-education. Aired September 8, 2016 on All Things Considered, National Public Radio.

Design Center Colorado. (2016). Design, build, invent, University of Colorado Boulder. Retrieved November 28, 2016 from https://www.designcenter.colorado.edu/about.

Ellis, J., Fosdick, B., K., \& Rasmussen, C. (2016). Women 1.5 times more likely to leave STEM pipeline after calculus compared to men: lack of mathematical confidence a potential culprit. PLoS One, 11(7), e 0157447. doi:10.1371/journal.pone.0157447.

George Mason University. Course syllabus: ENGR 107: Introduction to Engineering, Fall 2015. Retrieved January 22, 2017 from https://ece.gmu.edu/sites/ece/files/syllabus/9365/engr107-003-fall2015-syllabus.pdf.

Hill, C., Corbett, C., \& St. Rose, A. (2010). Why so few?: women in science, technology, engineering, and mathematics. Washington, D.C: AAUW.

Jones, B., Ruff, C., \& Paretti, M. (2013). The impact of engineering identification and stereotypes on undergraduate women's achievement and persistence in engineering. Social Psychology of Education, 16(3), 471-493. doi:10.1007/s11218013-9222-x.

Meiksins, P., P. Layne, E. Camargo, and K. Snead. (2013). Women in engineering: a review of the 2012 literature. Society of Women Engineers.

Meyer, M., \& Marx, S. (2014). Engineering Dropouts: A qualitative examination of why undergraduates leave engineering. Journal of Engineering Education, 103(4), 525-548. doi:10.1002/jee.20054. 
Mills, J., \& Ayre, M. (2003). Implementing an inclusive curriculum for women in engineering education. Journal of Professional Issues in Engineering Education and Practice, 129(4), 203-210. doi:10.1061/(asce)10523928(2003)129:4(203).

National Science Foundation, National Center for Science and Engineering Statistics. (2017). Women, minorities, and persons with disabilities in science and engineering: updated January 30, 2017. Retrieved February 10, 2017 from https://www.nsf.gov/statistics/2017/nsf17310/.

National Science Foundation, National Science Board. Science \& engineering indicators 2016. (2016). Retrieved February 10, 2017 from https://www.nsf.gov/statistics/2016/nsb20161/\#/.

Orr, M., K, Ngambeki, I., Long, R. A., \& Ohland, M. W. (2011). Performance trajectory of students in the engineering disciplines. 2011 Frontiers in Education Conference (FIE), S3H 1-5.

Osborne, J. W., \& Jones, B. D. (2011). Identification with academics and motivation to achieve in school: how the structure of the self influences academic outcomes. Educational Psychology Review, 23(1), 131-158. doi:10.1007/s10648-0119151-1.

Ro, H., \& D. Knight. (2016). Gender differences in learning outcomes from the college experiences of engineering students. Journal of Engineering Education, 105(3), 478-507. Doi:10.1002/jee.20125.

Shealy, T., Valdes-Vasquez, R., Klotz, L., Potvin, G., Godwin, A., Cribbs, J., \& Hazari, Z. (2016). Career Outcome Expectations Related to Sustainability among Students Intending to Major in Civil Engineering. Journal of Professional Issues in Engineering Education and Practice, 142(1). doi:10.1061/(asce)ei.1943-5541.0000253.

Silbey, Susan. (2016). Why do so many women who study engineering leave the field?. Harvard Business Review. Retrieved from https://hbr.org/2016/08/why-do-so-many-women-who-study-engineering-leave-the-field?r.

Sonnert, G., Fox, M. F., \& Adkins, K. (2007). Undergraduate women in science and engineering: effects of faculty, fields, and institutions over time. Social Science Quarterly, 88(5), 1333-1356. doi:10.1111/j.1540-6237.2007.00505.x.

$\mathrm{Su}$, X., Johnson, J., \& Bozeman, B. (2015). Gender diversity strategy in academic departments: exploring organizational determinants. Higher Education, 69(5), 839-858. doi:10.1007/s10734-014-9808-z.

University of Florida Office of Institutional Planning and Research. (2016). Degrees awarded. Retrieved December 18, 2016 from http://ir.aa.ufl.edu/degrees-grades.

University of Florida, Herbert Wertheim College of Engineering. (2017a). Introduction to design and programming. Retrieved February 14, 2017 from https://www.eng.ufl.edu/students/students/state-college-partnerships/gator-engineering-santafe/academic-components/introduction-to-engineering-design-and-programming/.

University of Florida. (2017b). GRiP: 3D Printed Assistive Devices through the University of Florida. Retrieved February 17, 2017 from http:/gripuf.com/. 